Research Perspective

\title{
COVID-19 and chronological aging: senolytics and other anti-aging drugs for the treatment or prevention of corona virus infection?
}

\author{
Camillo Sargiacomo ${ }^{1}$, Federica Sotgia ${ }^{1}$, Michael P. Lisanti ${ }^{1}$ \\ ${ }^{1}$ Translational Medicine, School of Science, Engineering and Environment (SEE), University of Salford, Greater \\ Manchester, United Kingdom
}

Correspondence to: Federica Sotgia, Michael P. Lisanti; email: $\underline{\text { fsotgia@gmail.com, michaelp.lisanti@gmail.com }}$

Keywords: COVID-19, corona virus, aging, senescence, senolytic drug therapy, prevention, viral replication, drug repurposing, antibiotic, Azithromycin, Hydroxy-chloroquine, Rapamycin, Doxycycline, Quercetin

Abbreviations: SASP: senescence-associated secretory phenotype

Received: March 20, 2020

Accepted: March 29, 2020

Published: March 30, 2020

Copyright: Sargiacomo et al. This is an open-access article distributed under the terms of the Creative Commons Attribution License (CC BY 3.0), which permits unrestricted use, distribution, and reproduction in any medium, provided the original author and source are credited.

\section{ABSTRACT}

COVID-19, also known as SARS-CoV-2, is a new emerging zoonotic corona virus of the SARS (Severe Acute Respiratory Syndrome) and the MERS (Middle East Respiratory Syndrome) family. COVID-19 originated in China and spread world-wide, resulting in the pandemic of 2020. For some reason, COVID-19 shows a considerably higher mortality rate in patients with advanced chronological age. This begs the question as to whether there is a functional association between COVID-19 infection and the process of chronological aging. Two host receptors have been proposed for COVID-19. One is CD26 and the other is ACE-2 (angiotensin-converting enzyme 2). Interestingly, both CD26 and the angiotensin system show associations with senescence. Similarly, two proposed therapeutics for the treatment of COVID-19 infection are Azithromycin and Quercetin, both drugs with significant senolytic activity. Also, Chloroquine-related compounds inhibit the induction of the well-known senescence marker, Beta-galactosidase. Other anti-aging drugs should also be considered, such as Rapamycin and Doxycycline, as they behave as inhibitors of protein synthesis, blocking both SASP and viral replication. Therefore, we wish to speculate that the fight against COVID-19 disease should involve testing the hypothesis that senolytics and other anti-aging drugs may have a prominent role in preventing the transmission of the virus, as well as aid in its treatment. Thus, we propose that new clinical trials may be warranted, as several senolytic and anti-aging therapeutics are existing FDA-approved drugs, with excellent safety profiles, and would be readily available for drug repurposing efforts. As Azithromycin and Doxycycline are both commonly used antibiotics that inhibit viral replication and IL-6 production, we may want to consider this general class of antibiotics that functionally inhibits cellular protein synthesis as a side-effect, for the treatment and prevention of COVID-19 disease.

The earliest retrospective study of the COVID-19 outbreak in Wuhan, China, published in the Lancet, was among one of the first clinical studies to identify older age as a significant risk factor for in-hospital mortality, suggesting that advanced chronological age may play an epidemiological role in patient clinical outcomes [1].
Mortality was also associated with other co-morbidities, normally considered to be aging-associated diseases, such as diabetes or coronary heart disease, as well as a critical inflammatory mediator of the senescenceassociated secretory phenotype (SASP), namely IL-6 [1]. 
This specific association of COVID-19 fatality with advanced chronological age was directly validated by the CDC in the US population [2] and published in the Morbidity and Mortality Weekly Report (MMWR) on the $18^{\text {th }}$ of March, as follows: "This first preliminary description of outcomes among patients with COVID19 in the United States indicates that fatality was highest in persons aged $\geq 85$, ranging from $10 \%$ to $27 \%$, followed by $3 \%$ to $11 \%$ among persons aged $65-84$ years, $1 \%$ to $3 \%$ among persons aged $55-64$ years, $<1 \%$ among persons aged 20-54 years, and no fatalities among persons aged $\leq 19$ years".

\section{What could be the biological mechanism(s) by which the COVID-19 virus preferentially targets patients with advanced chronological age?}

Two host receptors have been proposed for COVID-19. One is CD26 [3] and the other is ACE-2 (angiotensinconverting enzyme 2) [4]. Interestingly, both CD26 and the angiotensin system show associations with senescence. For example, ACE-2 is a known inhibitor of cell proliferation and the angiotensin system is upregulated in both premature and replicative senescence [5,6]. Remarkably, CD26 is known to be a bonafide cell surface marker of senescent cells [7]. Similarly, myofibroblasts (which are considered to be senescent and pro-fibrotic cells) also over-express CD26 and ACE-2 [8,9]. Senescent cells produce large amounts of inflammatory cytokines, as a result of the senescence-associated secretory phenotype (SASP), including IL-6.

Interestingly, the host receptor for MERS-CoV, a highly-related corona virus, is CD26, also known as dipeptidyl-peptidase IV (DPP4) [10-12]. Genetic evidence, including functional studies of existing CD26 human polymorphisms and humanized CD26 transgenic mouse animal models, has directly shown that CD26 is the functional host receptor for MERS-CoV, which is specifically required for host cell attachment, entry and, therefore, productive host cell infections, as well as species restrictions [10-12] Moreover, recent structural studies predict that the COVID-19 spike glycoproteins also directly interact with host cell CD26 [3].

Thus, one hypothesis is that the COVID-19 virus significantly increases mortality in patients with advanced chronological age, because these patients have an increased number of senescent lung cells, which are the host target for COVID-19 viral infection. Interestingly, senescent cells also show an increased propensity for enhanced protein synthesis, which is required to produce SASP inflammatory mediators, which would make senescent cells an ideal host target for efficient viral replication.
Therefore, it would be predicted that senolytic drugs could have a beneficial effect for the treatment and/or prevention of COVID-19 disease. Is there any evidence to support this attractive hypothesis?

Recently, a clinical trial was conducted using COVID19 positive hospitalized patients, which assessed COVID-19 virus production in response to treatment with two FDA-approved drugs, namely Hydroxychloroquine (Plaquenil) and Azithromycin (Z-PAC) [13]. Hydroxy-chloroquine alone, at the standard dosages, was surprisingly effective in reducing COVID19 viral production. However, the combination of Hydroxy-chloroquine and Azithromycin appeared to be even more effective. The mechanism(s) by which this drug combination halts COVID-19 virus production remains unknown.

\section{What is the known relationship between Hydroxy- chloroquine, Azithromycin and senescence?}

Chloroquine and its derivatives, such as Hydroxychloroquine, alkalinize the $\mathrm{pH}$ in lysosomes, which accumulate in large numbers in senescent cells. This Chloroquine-induced alkalinization functionally prevents the induction and accumulation of one of the most widely-recognized markers of senescence, known as beta-galactosidase (Beta-Gal), a lysosomal enzyme [14]. Hydroxy-chloroquine is also used clinically for the treatment of chronic inflammatory diseases, such as Sjögren's syndrome, and it effectively reduces the salivary and serum levels of IL-6, a key component of the SASP [15].

Azithromycin also has a key relationship with senescence [16]. Recent studies have shown that Azithromycin, and the closely related drug Roxithromycin, both act as senolytic drugs that can target and selectively remove senescent cells, with an efficiency of nearly $97 \%$ [16]. Interestingly, in patients with Cystic Fibrosis, Azithromycin is known to have an anti-fibrotic effect, which significantly extends their lifespan, by targeting myofibroblast cells (Discussed in Ref [16]). Cystic Fibrosis patients normally die from lung inflammation and fibrosis, resulting in lung stiffening and an inability to respire. Fibrosis is also known to be an age-related phenomenon, associated with increased numbers of myofibroblasts (senescent cells), which increases with chronological age. Azithromycin functionally acts as an anti-inflammatory drug and reduces SASP mediators, such as IL-1beta and IL-6 $[17,18]$. This may be due to Azithromycin's high senolytic activity and/or inhibition of protein synthesis.

Interestingly, Azithromycin also inhibits the replication of other viruses, such as Zika and Ebola [19-21]. If this 
inhibitory activity reflects Azithromycin's ability to inhibit protein synthesis, then other inhibitors of protein synthesis, such as Rapamycin, should be considered as well (see Supplementary Figure 1).

Consistent with this hypothesis, Rapamycin has been shown to potently inhibit HIV-1 replication [22]. Moreover, Rapamycin shows key anti-aging properties and prevents the onset of senescence [23-25].

Similarly, Doxycycline inhibits mammalian cell protein synthesis as an off-target side effect [26], effectively blocks replication of Dengue virus [27], reduces IL-6 serum levels during viral infection [28] and behaves as an anti-aging drug [29]. Therefore, Doxycycline could provide another inexpensive, but very attractive, option for the treatment or prevention of COVID-19 infection.

Finally, a recent study, using supercomputer-based in silico drug-docking to the COVID-19 viral spike protein identified Quercetin as a potential binding partner, to reduce virus-host interactions, with ACE-2 [30]. Quercetin has also been identified as a dietary supplement with senolytic properties [31].

Therefore, we propose that the clinical relationship between advanced chronological age and COVID-19 mortality may suggest the use of senolytic or anti-aging drugs in COVID-19 disease prevention (Figure 1). Of course, clinical trials will be necessary to test this attractive, but speculative, hypothesis experimentally.
Fortunately, several promising senolytic and other antiaging drugs are already FDA-approved for other disease indications. This approach can significantly accelerate their clinical evaluation through drug repurposing, as they have already been evaluated for their clinical safety, in Phase I trials. As such, these FDA-approved drugs can directly enter into Phase II clinical trials, to test their potential efficacy against COVID-19. Alternatively, in the United States, FDA-approved drugs can be medically-prescribed for an "off-label" use, at the discretion of the practicing physician.

Interestingly, SARS-CoV, a close relative of COVID-19 (SARS-CoV-2), also shows increased susceptibility in patients with advanced chronological age, which has been recapitulated in a mouse animal model of disease pathogenesis [32,33]. Briefly, in young mice (4-8 weeks-old), the SARS-CoV infection is cleared very rapidly, which is accompanied by mild pneumonitis, without the activation of cytokine production. In contrast, in older mice (12-14-months-old), productive infection with SARS-CoV led to a more severe interstitial pneumonitis, with alveolar damage, significant fibrosis and scarring, as well as severe activation of cytokine production, including TNF- $\alpha$, IL6, CCL-2, CCL-3, CXCL-10, and IFN- $\gamma[32,33]$. This latter mouse model more closely resembles the SARS$\mathrm{CoV}$ disease phenotype, observed in patients with advanced chronological age. Therefore, such a mouse model would also be useful for testing the efficacy of new therapies, specifically targeting the senescent cell

\section{HYPOTHESIS}

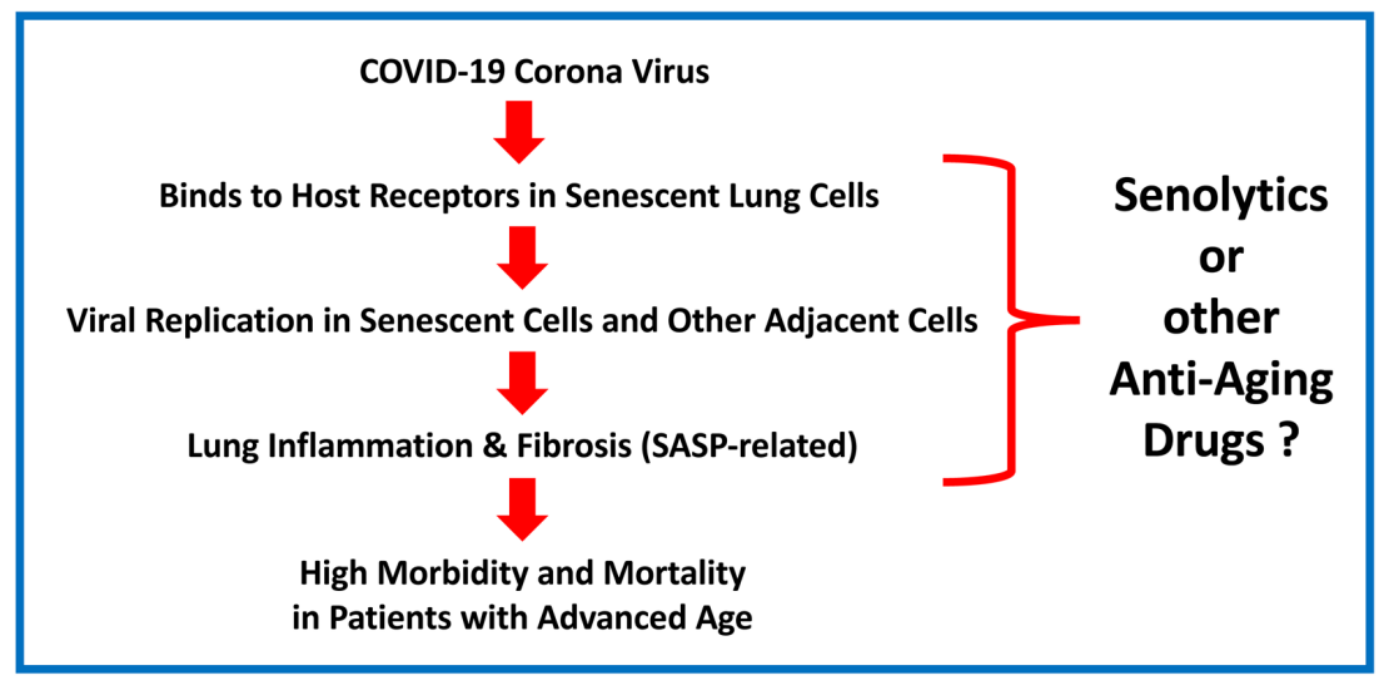

Figure 1. What is the relationship between COVID-19 and advanced chronological age? Here, we suggest that the COVID-19 corona virus preferentially targets senescent lung cells, resulting in increased morbidity and mortality in the aging population. One possible solution for prevention/treatment would be the use of senolytics or other anti-aging drugs. Testing this hypothesis will require the necessary clinical trials, with a focus on drug repurposing. 
population and SASP, for the repurposing of these FDA-approved anti-aging drugs.

\section{Disclaimer}

This perspective is intended for a professional audience, to stimulate new ideas and to aid the global efforts to develop effective treatments for COVID-19 disease. This article does not represent medical advice or recommendations to patients. The media should exercise caution and seek expert medical advice for interpretation, when referring to this article.

\section{Note Added in Proof}

While this Perspective was being reviewed, another clinical trial was published online, confirming the efficacy of Hydroxy-chloroquine and Azithromycin, for treating COVID-19 patients, in a larger cohort of 80 patients. See the following article:

Philippe Gautret, Jean-Christophe Lagier, Philippe Parola, Van Thuan Hoang, Line Meddeb, Jacques Sevestre, Morgane Mailhe, Barbara Doudier, Camille Aubry, Sophie Amrane, Piseth Seng, Marie Hocquart, Julie Finance, Vera Esteves Vieira, Hervé Tissot Dupont, Stéphane Honoré, Andreas Stein, Matthieu Million, Philippe Colson, Bernard La Scola, Véronique Veit, Alexis Jacquier, Jean-Claude Deharo, Michel Drancourt and Didier Raoult. Clinical and microbiological effect of a combination of hydroxychloroquine and azithromycin in 80 COVID-19 patients with at least a six-day follow up: an observational study.

https://www.mediterranee-infection.com/wp-

content/uploads/2020/03/COVID-IHU-2-1.pdf

\section{ACKNOWLEDGEMENTS}

We are grateful to Rumana Rafiq for her kind and dedicated assistance in keeping the Translational Medicine Laboratory at the University of Salford running very smoothly. We would like to thank the Foxpoint Foundation (Canada) and the Healthy Life Foundation (UK) for their philanthropic donations towards new equipment and infrastructure in the Translational Medicine Laboratory at the University of Salford.

\section{CONFLICTS OF INTEREST}

The authors have no conflicts of interest to declare.

\section{FUNDING}

The Lisanti/Sotgia Laboratory is supported by research grant funding, provided by Lunella Biotech, Inc.

\section{REFERENCES}

1. Zhou F, Yu T, Du R, Fan G, Liu Y, Liu Z, Xiang J, Wang Y, Song B, Gu X, Guan L, Wei Y, Li H, et al. Clinical course and risk factors for mortality of adult inpatients with COVID-19 in Wuhan, China: a retrospective cohort study. Lancet. 2020; 395:S0140-6736(20)30566-3. https://doi.org/10.1016/S0140-6736(20)30566-3 PMID: $\underline{32171076}$

2. Severe Outcomes Among Patients with Coronavirus Disease. 2019 (COVID-19) - United States, February 12-March 16, 2020. MMWR Morb Mortal Wkly Rep. 2020; 69:343-46. https://doi.org/10.15585/mmwr.mm6912e2 PMID: $\underline{32214079}$

3. Vankadari N, Wilce JA. Emerging WuHan (COVID-19) coronavirus: glycan shield and structure prediction of spike glycoprotein and its interaction with human CD26. Emerg Microbes Infect. 2020; 9:601-04. https://doi.org/10.1080/22221751.2020.1739565 PMID: $\underline{32178593}$

4. Tai W, He L, Zhang X, Pu J, Voronin D, Jiang S, Zhou Y, Du L. Characterization of the receptor-binding domain (RBD) of 2019 novel coronavirus: implication for development of RBD protein as a viral attachment inhibitor and vaccine. Cell Mol Immunol. 2020. [Epub ahead of print] https://doi.org/10.1038/s41423-0200400-4 PMID:32203189

5. Song J, Hu B, Qu H, Wang L, Huang X, Li M, Zhang M. Upregulation of angiotensin converting enzyme 2 by shear stress reduced inflammation and proliferation in vascular endothelial cells. Biochem Biophys Res Commun. 2020. [Epub ahead of print]. https://doi.org/10.1016/j.bbrc.2020.02.151 PMID: $\underline{32169277}$

6. Khemais-Benkhiat $S$, Idris-Khodja N, Ribeiro TP, Silva GC, Abbas M, Kheloufi M, Lee JO, Toti F, Auger C, Schini-Kerth VB, Gerontol A. The Redox-sensitive Induction of the Local Angiotensin System Promotes Both Premature and Replicative Endothelial Senescence: Preventive Effect of a Standardized Crataegus Extract. J Gerontol A Biol Sci Med Sci. 2016; 71:1581-90. https://doi.org/10.1093/gerona/glv213 PMID:26672612

7. Kim KM, Noh JH, Bodogai $M$, Martindale JL, Yang $X$, Indig FE, Basu SK, Ohnuma K, Morimoto $\mathrm{C}$, Johnson PF, Biragyn A, Abdelmohsen K, Gorospe $M$. Identification of senescent cell surface targetable protein DPP4. Genes Dev. 2017; 31:1529-34. https://doi.org/10.1101/gad.302570.117 PMID:28877934

8. Guy JL, Lambert DW, Turner AJ, Porter KE. Functional angiotensin-converting enzyme 2 is expressed in 
human cardiac myofibroblasts. Exp Physiol. 2008; 93:579-88.

https://doi.org/10.1113/expphysiol.2007.040139 PMID:18223028

9. Mah W, Jiang G, Olver D, Gallant-Behm C, Wiebe C, Hart DA, Koivisto L, Larjava $H$, Häkkinen L. Elevated CD26 Expression by Skin Fibroblasts Distinguishes a Profibrotic Phenotype Involved in Scar Formation Compared to Gingival Fibroblasts. Am J Pathol. 2017; 187:1717-35.

https://doi.org/10.1016/j.ajpath.2017.04.017 PMID: 28641076

10. Kleine-Weber $H$, Schroeder $S$, Krüger $N$, Prokscha $A$, Naim HY, Müller MA, Drosten C, Pöhlmann $S$, Hoffmann M. Polymorphisms in dipeptidyl peptidase 4 reduce host cell entry of Middle East respiratory syndrome coronavirus. Emerg Microbes Infect. 2020; 9:155-68.

https://doi.org/10.1080/22221751.2020.1713705 PMID:31964246

11. Kim J, Yang $\mathrm{YL}$, Jeong $\mathrm{Y}$, Jang $\mathrm{YS}$. Middle East respiratory syndrome-coronavirus infection into established hDDP4-transgenic mice accelerates lung damage via activation of the pro-inflammatory response and pulmonary fibrosis. I Microbiol Biotechnol. 2020; 30:427-38.

https://doi.org/10.4014/jmb.1910.10055 PMID:31838832

12. van Doremalen $\mathrm{N}$, Miazgowicz $\mathrm{KL}$, Milne-Price $\mathrm{S}$, Bushmaker T, Robertson S, Scott D, Kinne J, McLellan JS, Zhu J, Munster VJ. Host species restriction of Middle East respiratory syndrome coronavirus through its receptor, dipeptidyl peptidase 4. J Virol. 2014; 88:9220-32.

https://doi.org/10.1128/JVI.00676-14

PMID:24899185

13. Gautret $P$, Lagier JC, Parola P, Hoang VT, Meddeb L, Mailhe M, Doudier B, Courjon J, Giordanengo V, Vieira VE, Dupont HT, Honoré $S$, Colson $P$, et al. Hydroxychloroquine and azithromycin as a treatment of COVID-19: results of an open-label nonrandomized clinical trial. Int J Antimicrob Agents. 2020; [Epub ahead of print].

https://doi.org/10.1016/j.ijantimicag.2020.105949 PMID:32205204

14. Kurz DJ, Decary S, Hong Y, Erusalimsky JD. Senescence-associated (beta)-galactosidase reflects an increase in lysosomal mass during replicative ageing of human endothelial cells. J Cell Sci. 2000; 113:3613-22. PMID: 11017877

15. Tishler M, Yaron I, Shirazi I, Yaron M. Hydroxychloroquine treatment for primary Sjögren's syndrome: its effect on salivary and serum inflammatory markers. Ann Rheum Dis. 1999; 58:253-56. https://doi.org/10.1136/ard.58.4.253 PMID: 10364906

16. Ozsvari B, Nuttall JR, Sotgia F, Lisanti MP. Azithromycin and Roxithromycin define a new family of "senolytic" drugs that target senescent human fibroblasts. Aging (Albany NY). 2018; 10:3294-307. https://doi.org/10.18632/aging.101633 PMID:30428454

17. Mosquera RA, De Jesus-Rojas W, Stark JM, Yadav A, Jon CK, Atkins CL, Samuels CL, Gonzales TR, McBeth KE, Hashmi SS, Garolalo R, Colasurdo GN. Role of prophylactic azithromycin to reduce airway inflammation and mortality in a RSV mouse infection model. Pediatr Pulmonol. 2018; 53:567-74. https://doi.org/10.1002/ppul.23956 PMID:29405608

18. Tang F, Li R, Xue J, Lan J, Xu H, Liu Y, Zhou L, Lu Y. Azithromycin attenuates acute radiation-induced lung injury in mice. Oncol Lett. 2017; 14:5211-20. https://doi.org/10.3892/ol.2017.6813

PMID:29098024

19. Retallack H, Di Lullo E, Arias C, Knopp KA, Laurie MT, Sandoval-Espinosa C, Mancia Leon WR, Krencik R, Ullian EM, Spatazza J, Pollen AA, Mandel-Brehm C, Nowakowski TJ, et al. Zika virus cell tropism in the developing human brain and inhibition by azithromycin. Proc Natl Acad Sci USA. 2016; 113:14408-13.

https://doi.org/10.1073/pnas.1618029113

PMID:27911847

20. Bosseboeuf E, Aubry M, Nhan T, de Pina JJ, Rolain JM, Raoult D, Musso D. Azithromycin Inhibits the Replication of Zika Virus. J Antivir Antiretrovir. 2018; 10:6-11. $\quad$ https://doi.org/10.4172/1948$\underline{5964.1000173}$

21. Madrid PB, Panchal RG, Warren TK, Shurtleff AC, Endsley AN, Green CE, Kolokoltsov A, Davey R, Manger ID, Gilfillan L, Bavari S, Tanga MJ. Evaluation of Ebola Virus Inhibitors for Drug Repurposing. ACS Infect Dis. 2015; 1:317-26.

https://doi.org/10.1021/acsinfecdis.5b00030 PMID:27622822

22. Roy J, Paquette JS, Fortin JF, Tremblay MJ. The immunosuppressant rapamycin represses human immunodeficiency virus type 1 replication. Antimicrob Agents Chemother. 2002; 46:3447-55. https://doi.org/10.1128/AAC.46.11.3447-3455.2002 PMID:12384349

23. Blagosklonny MV. Rapamycin for longevity: opinion article. Aging (Albany NY). 2019; 11:8048-67. https://doi.org/10.18632/aging.102355

PMID:31586989 
24. Blagosklonny MV. Rapamycin, proliferation and geroconversion to senescence. Cell Cycle. 2018; 17:2655-65.

https://doi.org/10.1080/15384101.2018.1554781

PMID:30541374

25. Demidenko ZN, Zubova SG, Bukreeva EI, Pospelov VA, Pospelova TV, Blagosklonny MV. Rapamycin decelerates cellular senescence. Cell Cycle. 2009; 8:1888-95. https://doi.org/10.4161/cc.8.12.8606 PMID: 19471117

26. Peiris-Pagès $M$, Ozsvári $B$, Sotgia $F$, Lisanti MP. Mitochondrial and ribosomal biogenesis are new hallmarks of stemness, oncometabolism and biomass accumulation in cancer: mito-stemness and ribostemness features. Aging (Albany NY). 2019; 11:4801-35. https://doi.org/10.18632/aging.102054 PMID: $\underline{31311889}$

27. Rothan HA, Mohamed Z, Paydar M, Rahman NA, Yusof R. Inhibitory effect of doxycycline against dengue virus replication in vitro. Arch Virol. 2014; 159:711-18. $\quad$ https://doi.org/10.1007/s00705-0131880-7 PMID:24142271

28. Fredeking TM, Zavala-Castro JE, González-Martínez $P$, Moguel-Rodríguez W, Sanchez EC, Foster MJ, DiazQuijano FA. Dengue Patients Treated with Doxycycline Showed Lower Mortality Associated to a Reduction in IL-6 and TNF Levels. Recent Pat Antiinfect Drug Discov. 2015; 10:51-58. https://doi.org/10.2174/1574891X106661504101538 39 PMID:25858261

29. Houtkooper RH, Mouchiroud L, Ryu D, Moullan N, Katsyuba E, Knott G, Williams RW, Auwerx J. Mitonuclear protein imbalance as a conserved longevity mechanism. Nature. 2013; 497:451-57. https://doi.org/10.1038/nature12188 PMID:23698443

30. Smith M, Smith JC. Repurposing Therapeutics for COVID-19: Supercomputer-Based Docking to the SARS-CoV-2 Viral Spike Protein and Viral Spike Protein-Human ACE2 Interface. 2020. ChemRxiv. https://doi.org/10.26434/chemrxiv.11871402.v4

31. Cavalcante $M B$, Saccon TD, Nunes $A D$, Kirkland JL, Tchkonia T, Schneider A, Masternak MM. Dasatinib plus quercetin prevents uterine age-related dysfunction and fibrosis in mice. Aging (Albany NY). 2020; 12:2711-22.

https://doi.org/10.18632/aging.102772

PMID:31955151

32. Baas T, Roberts A, Teal TH, Vogel L, Chen J, Tumpey TM, Katze MG, Subbarao K. Genomic analysis reveals age-dependent innate immune responses to severe acute respiratory syndrome coronavirus. J Virol. 2008; 82:9465-76.

https://doi.org/10.1128/JVI.00489-08

PMID:18632870

33. Chen J, Lau YF, Lamirande EW, Paddock CD, Bartlett JH, Zaki SR, Subbarao K. Cellular immune responses to severe acute respiratory syndrome coronavirus (SARS-CoV) infection in senescent BALB/c mice: CD4+ $T$ cells are important in control of SARS-CoV infection. J Virol. 2010; 84:1289-301.

https://doi.org/10.1128/JVI.01281-09

PMID: 19906920 


\section{SUPPLEMENTARY MATERIALS}

\section{Supplementary Figure}

\section{Cytokines and Viruses are both made of Proteins}

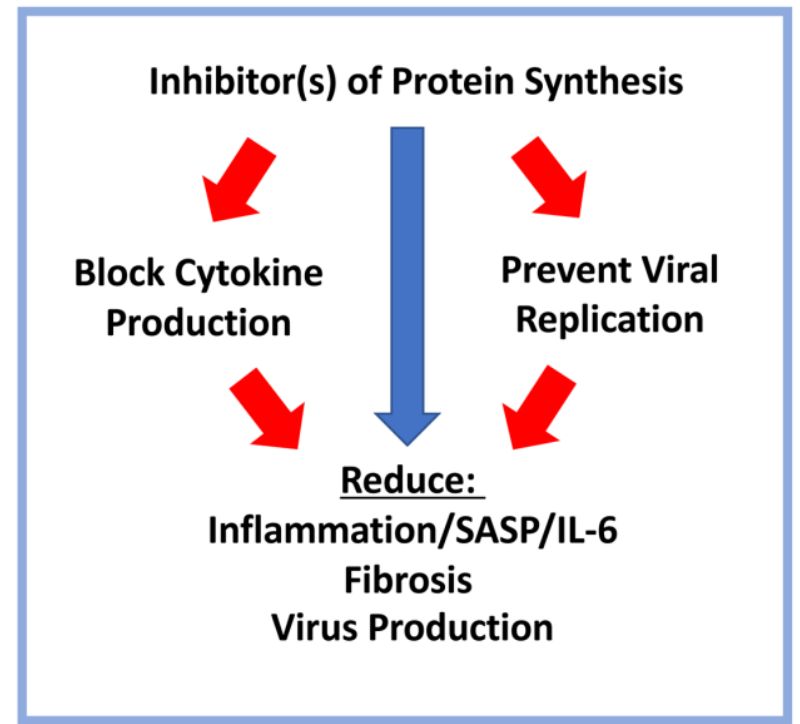

\section{Doxycycline, Azithromycin and Rapamycin All Inhibit Protein Synthesis All are FDA-Approved Drugs}

Supplementary Figure 1. Inhibitor(s) of protein synthesis block inflammation and viral replication. Azithromycin, Doxycycline and Rapamycin are all FDA-approved drugs that behave as inhibitors of protein synthesis and experimentally have been shown to reduce inflammation and viral replication. Mechanistically, this is because cytokines and viruses are both made of proteins. Both use the cellular ribosomes for protein translation. Inhibiting virus production should help to clinically reduce viral transmission to other patients. 